\title{
Partial Discharge Pattern of Various Defects Measured by Spiral Antenna as UHF External Sensor on 66 kV GIS Model
}

\author{
Umar Khayam ${ }^{1}$, Widya Anggoro Putro ${ }^{2}$, Sriyono ${ }^{2}$, Koji Urano $^{3}$, Chen Min $^{3}$, Suwarno ${ }^{1}$, \\ Masahiro Kozako ${ }^{4}$, and Masayuki Hikita ${ }^{4}$ \\ ${ }^{1}$ School of Electrical Engineering and Informatics, Institut Teknologi Bandung, Indonesia \\ ${ }^{2}$ PT PLN (Persero), Indonesia ${ }^{3}$ SE Technology, Hongkong \\ ${ }^{4}$ Department of Electrical Engineering, Kyushu Institute of Technology, Japan \\ umar@hv.ee.itb.ac.id
}

\begin{abstract}
This paper deals with partial discharge (PD) measurement in gas insulated switchgear (GIS) using spiral antenna as UHF external sensor. PD detection in UHF band is effective because it detects electromagnetic (EM) wave induced by PD with high $\mathrm{S} / \mathrm{N}$ ratio. External sensor was used to detect leaked $\mathrm{EM}$ wave signals from insulation spacer of GIS tank. The experiment was conducted in $66 \mathrm{kV}$ GIS model with metal type spacer. There is insulation window in the spacer. PD was generated by some artificial defects in GIS and an external PD source. The leaked EM wave propagated through spacer aperture was measured using spiral type sensor without filter and amplifier. The peak to peak value (Vpp) and the transmission rate of electromagnetic wave signals were evaluated. The PD patterns were observed. The results showed that the PD was detected by the spiral antenna. PD pattern was unique for each defect. These results are considered to be useful for enhancement of database PD diagnosis.

Keywords - partial discharge, external sensor, spiral antenna, UHF detection, PD pattern
\end{abstract}

\section{Introduction}

Detection of partial discharge (PD) is useful for condition monitoring of gas insulated switchgear (GIS) [1-8]. For the insulation diagnosis of GIS, the ultra-high frequency (UHF) method which detects PD induced electromagnetic wave (EM-wave) in the UHF band (300 $\mathrm{MHz}$ to several $\mathrm{GHz}$ ) with little noise influence, has rapidly developed in recent years [9-18]. It is necessary to install a sensor inside or set on the outside of a GIS tank to detect partial discharge (PD) signals that propagate inside a GIS. For GISs that have already been constructed, it is effective to use external diagnosis using EM-wave signals that radiate (leak) from the insulation spacer of the GIS tank [19]. For a metal spacer, there is usually an insulation aperture in the spacer which enables EM-wave to radiate. Some external sensors for PD detection in GIS have been examined recently such as bowtie antenna, horn antenna, and loop antenna [20-30].

In this research the spiral antenna was examined to measure PD in $66 \mathrm{kV}$ GIS model. PD was generated by some artificial PD sources; those are protrusion on the high voltage conductor, protrusion on the tank, floating electrode, free particle, void, particle on the spacer, and aerial/external defects. PD pattern was measured by spiral antenna as UHF sensors and observed by PD monitoring device. These results are considered to be useful for enhancement of database PD diagnosis.

\section{Experimental Setup}

A. GIS Model

The experimental setup was arranged as shown in Figure 1. The $66 \mathrm{kV}$ GIS model was used in the experiment. GIS $66 \mathrm{kV}$ structure is composed of coaxial cylindrical electrodes with high voltage conductors and insulating spacers. The GIS central conductor is $80 \mathrm{~mm}$ in diameter and GIS tank was $200 \mathrm{~mm}$ in diameter. Each gas section is $1000 \mathrm{~mm}$ in length, except for the end

Received: February $24^{\text {th }}, 2013$. Accepted: June $23^{\text {rd }}, 2014$ 
conductor with connected gas compartment with total length is $1500 \mathrm{~mm}$. The insulating spacer is made from epoxy resin with a cone-shaped structure (relative dielectric constant $=4$ ). The outer periphery of the insulating spacer is clad with aluminium and part of the epoxy resin is exposed bare. The exposed part of the epoxy resin (spacer aperture) is $65 \mathrm{~mm}$ in length and 15 $\mathrm{mm}$ width. The gas compartment was filled with $\mathrm{SF}_{6}$ gas at $0.15 \mathrm{MPa}$.

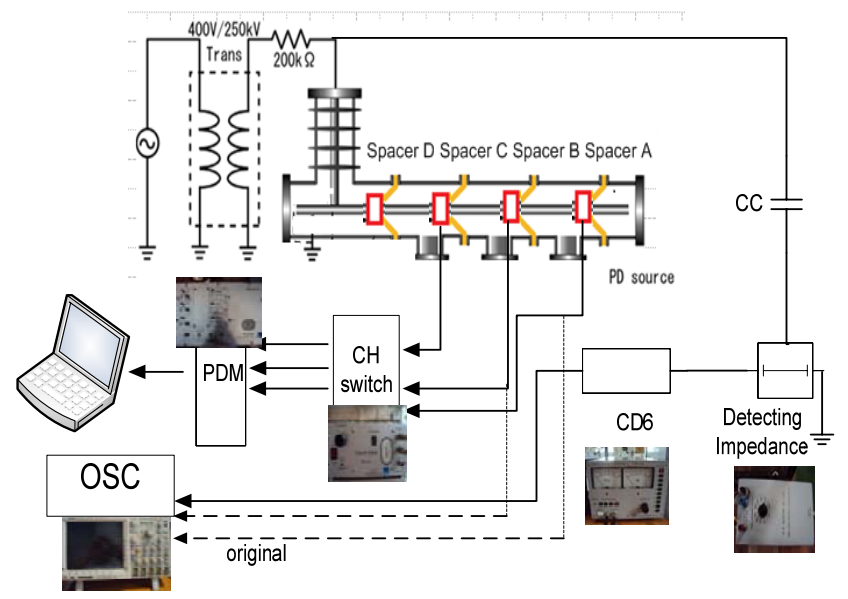

Figure 1. Experimental setup and condition

\section{B. PD charge calibration}

Before the main experiment, the charge calibration was conducted using a pulse calibrator as shown in Figure 2. The charge was injected from a pulse calibrator into GIS bushing and the output was measured by an oscilloscope. The charge calibration results are shown in Figure 3. The PD apparent charge can be estimated when the voltage measured using CD6 based on the conventional method (IEC 60270) is known.

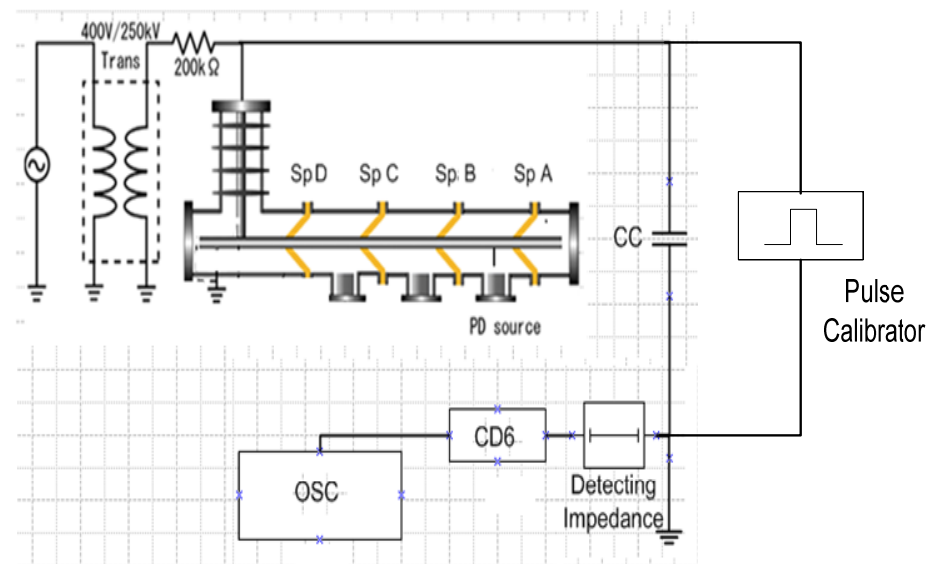

Figure 2. Charge calibration of experimental setup 


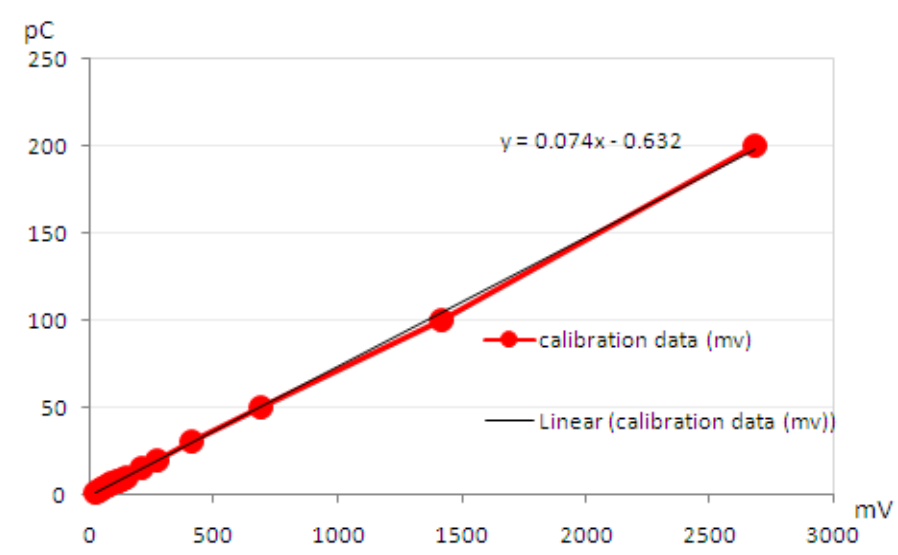

Figure 3. Charge calibration I (Volt \& mv)

\section{Spiral Antenna as UHF PD Sensor}

The leaked EM wave propagated through spacer aperture was measured using spiral type sensor. For PD pattern measurement, three spiral antennas as UHF sensors (named as A, B, C) placed on the aperture spacer. The sensors were connected to the channel switch as a power supply. The output of the channel switch was connected to PDM device and the oscilloscope and the computer. The envelope processing and amplification were processed in PDM device. The PD pattern was observed and recorded in the computer.

For transmission rate evaluation, two spiral sensors without envelope processing \& amplifier (called as original sensor) connected to spacer A and spacer B. The sensors were connected to an oscilloscope (oscilloscope Tektronix, DPO4104, $1 \mathrm{GHz}, 5 \mathrm{GS} / \mathrm{s}$ ). The PD detecting device (CD-6) based on conventional method IEC 60270 was used as comparison. We used limit resistance $200 \mathrm{k} \Omega$, coupling capacitor $2 \mathrm{nF}$, and RC detection impedance (R constant $=50 \mathrm{ohm}$ and $\mathrm{C}$ variable $=470 \mathrm{pF}$ ).

The voltage was converted into apparent charge based on the calibration result using the charge calibrator. Partial discharge was measured using partial discharge monitoring (PDM) device, oscilloscope voltage / current-time graph, and conventional method IEC 60270.

\section{Artificial PD Source}

Figure 4 shows seven artificial defects used in this experiment. Those are: protrusion on the high voltage conductor (POC), protrusion on the tank (POT), floating electrode (FLOATING), free metal particle (FMP), particle on the spacer (POS), void / delamination (DEL) and aerial defect (OUTSIDE).

Protrusion on the high voltage conductor (HVC) is a $5 \mathrm{~cm}$ needle electrode (Ogura) attached on the conductor. The curvature of the needle tip was $30^{\circ}$. The gap between the needle tip and the tank was $1 \mathrm{~cm}$. PDIV from above configuration was $6 \mathrm{kV}$. Protrusion on the tank was made similar with protrusion on the high voltage conductor. PDIV from protrusion on the tank was $11 \mathrm{kV}$.

Floating electrode defect made from steel with $20 \mathrm{~mm}$ in length was floating in SF6 gas by being tied to a piece of string attached to the side walls of the tank. The gap length between the conductor and the tip of maximum position of floating electrode was $5 \mathrm{~mm}$. PDIV for this model was $23 \mathrm{kV}$.

Two free metal particle defects made from steel with length $1 \mathrm{~cm}$ was attached to both end of a $12 \mathrm{~cm}$ string adhered in middle to the side wall. PDIV for this model was $15 \mathrm{kV}$.

Particle on the spacer is made from steel adhered to the top side of the spacer. The length of steel was $1 \mathrm{~cm}$ with the gap between the conductor and the spacer was $1 \mathrm{~cm}$. We placed a piece of spacer on the bottom side of tank with $5 \mathrm{~cm}$ in height. PDIV for this model was $45 \mathrm{kV}$. 
Void / delamination defect is made from resin with $0,3 \mathrm{~mm}$ air gap. The length of void was 3 $\mathrm{mm}$. We placed the resin connected to the conductor on the topside and grounded to the tank on the bottom side.

Aerial outside defect made from needle-plane electrode with gap $1 \mathrm{~mm}$ was directly connected to GIS. PDIV from this model was $3 \mathrm{kV}$.

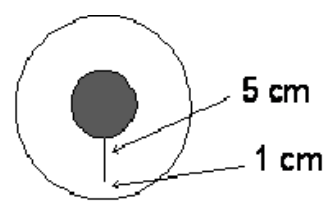

Protrusion on the high voltage conductor (HVC)

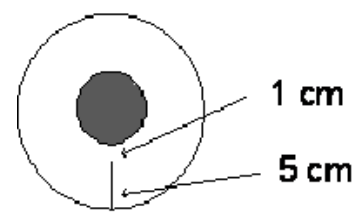

Protrusion on the Tank (TANK)

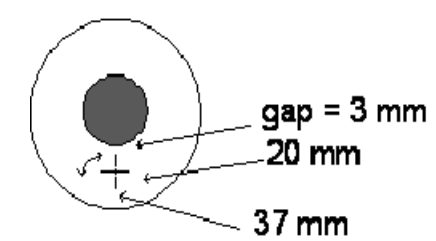

Floating electrode (FLOATING)

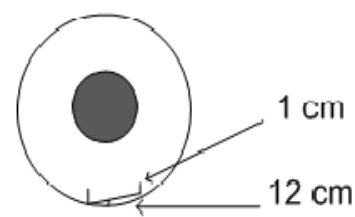

Free Metal Particle (FMP)

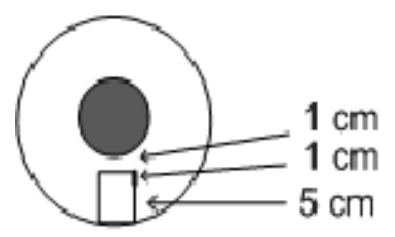

Particle on Spacer (POS) 

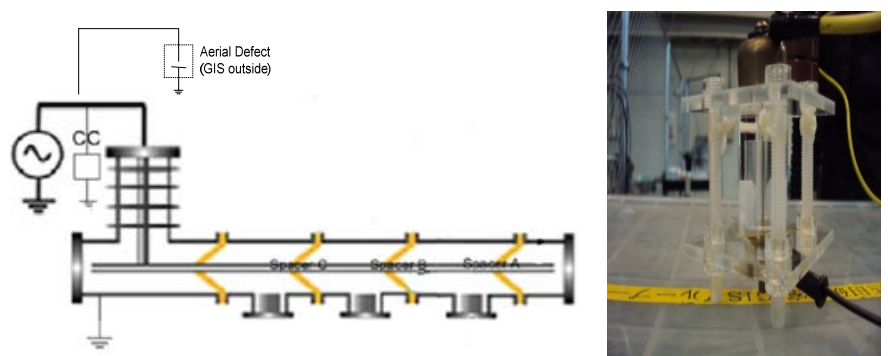

Defects on GIS outside (AERIAL)
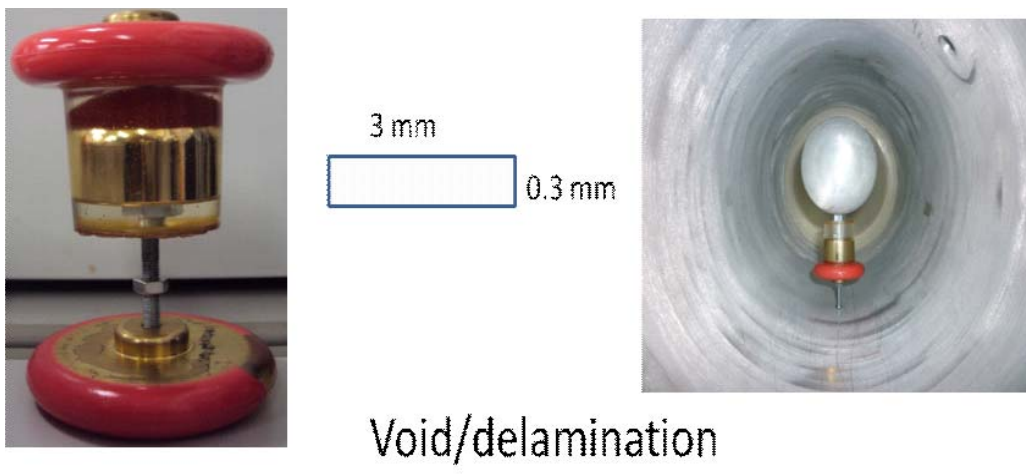

Delamination (DEL)

Figure 4. Seven different artificial PD defects

\section{Experimental Results}

Partial discharges are represented by several parameters: PD inception voltage (Vi) in [kV], phase angle of PD occurrence and PD number or PD frequency in a specific time or phase angle. Figures 5-11 show PD emitted EM waveform from the various defects.

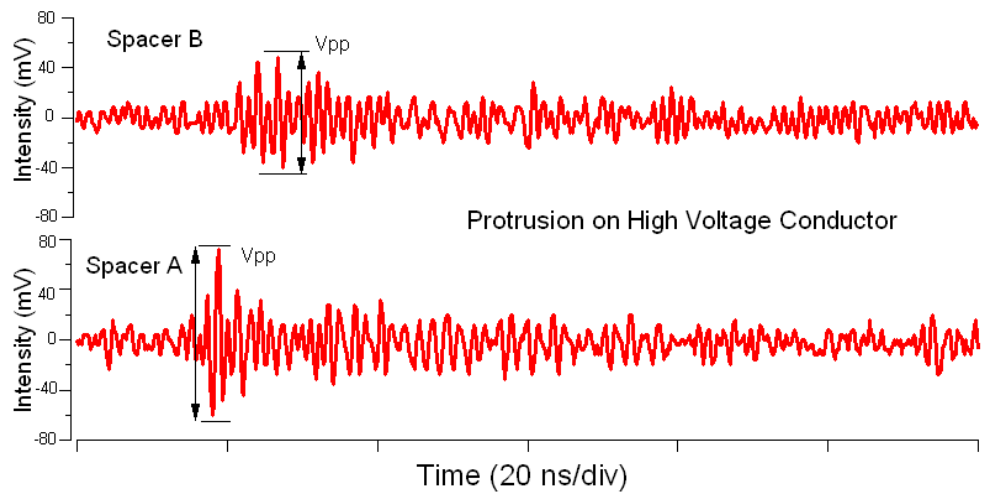

Figure 5. PD induced EM waveform from protrusion on high voltage conductor measured by external sensors in $66 \mathrm{kV}$ GIS model 


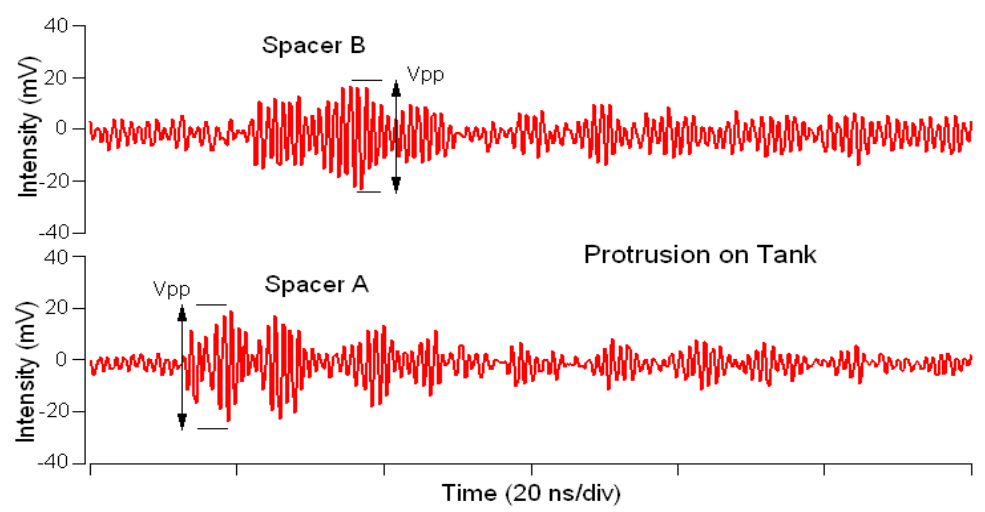

Figure 6. PD induced EM waveform from protrusion on the tank measured by external sensors in $66 \mathrm{kV}$ GIS model

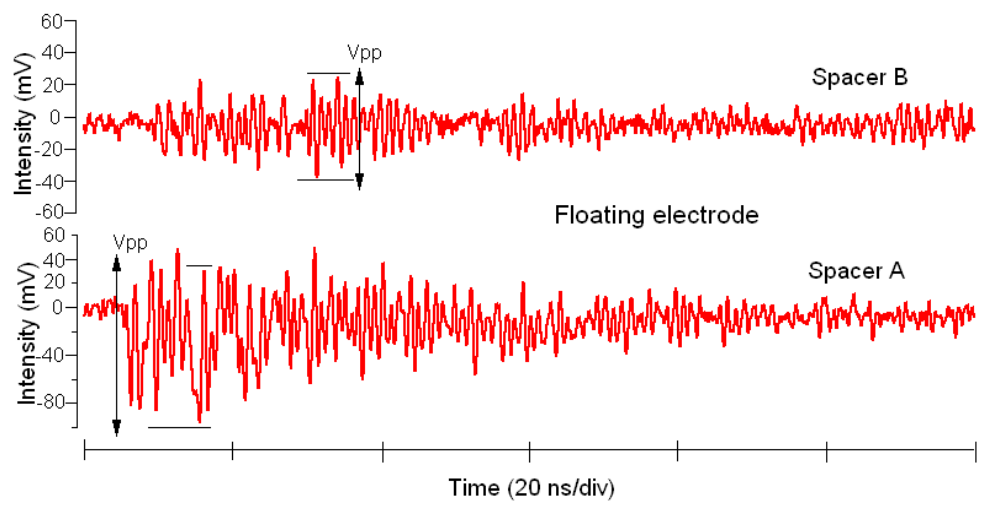

Figure 7. PD induced EM waveform from floating electrode measured by external sensors in $66 \mathrm{kV}$ GIS model

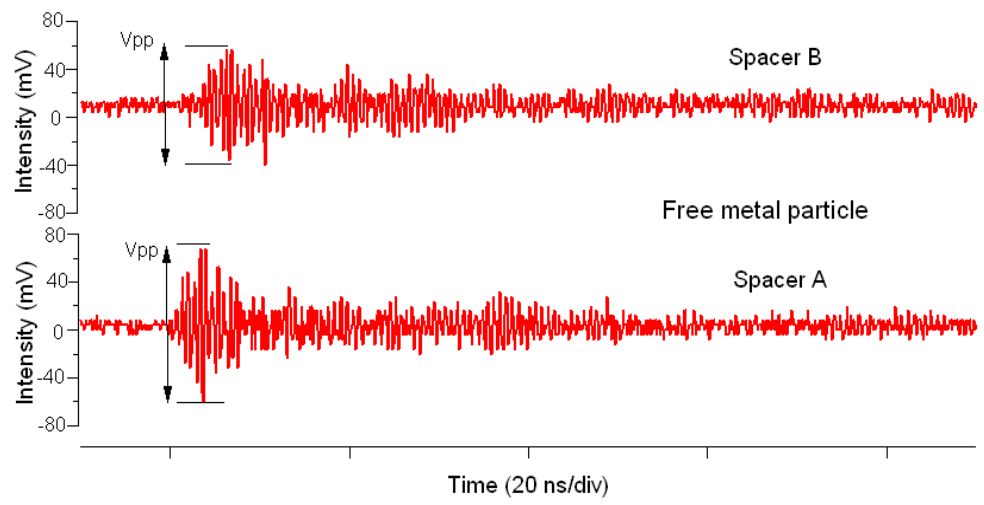

Figure 8. PD induced EM waveform from free metal particle measured by external sensors in $66 \mathrm{kV}$ GIS model 


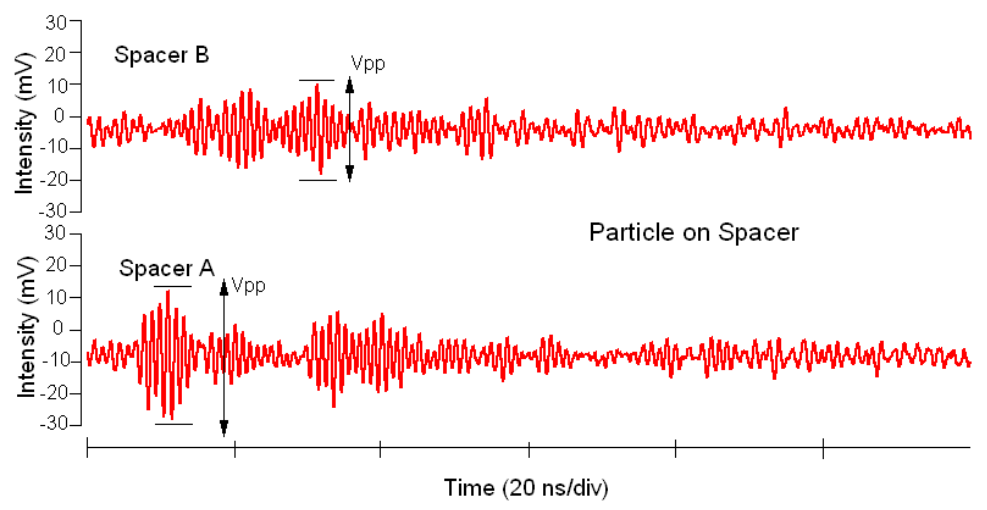

Figure 9. PD induced EM waveform from particle on the spacer measured by external sensors in $66 \mathrm{kV}$ GIS model

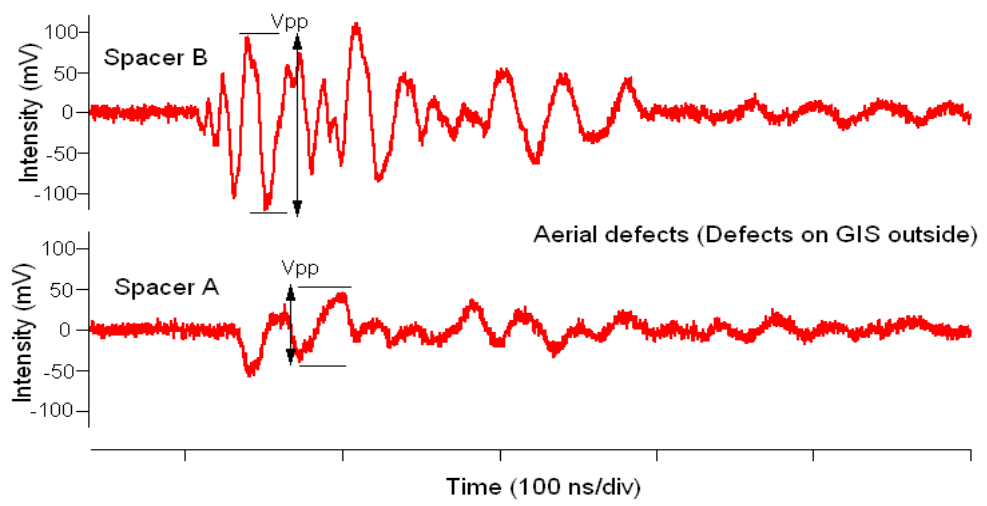

Figure 10. PD induced EM waveform from aerial defect (PD source outside GIS) measured by external sensors in $66 \mathrm{kV}$ GIS model

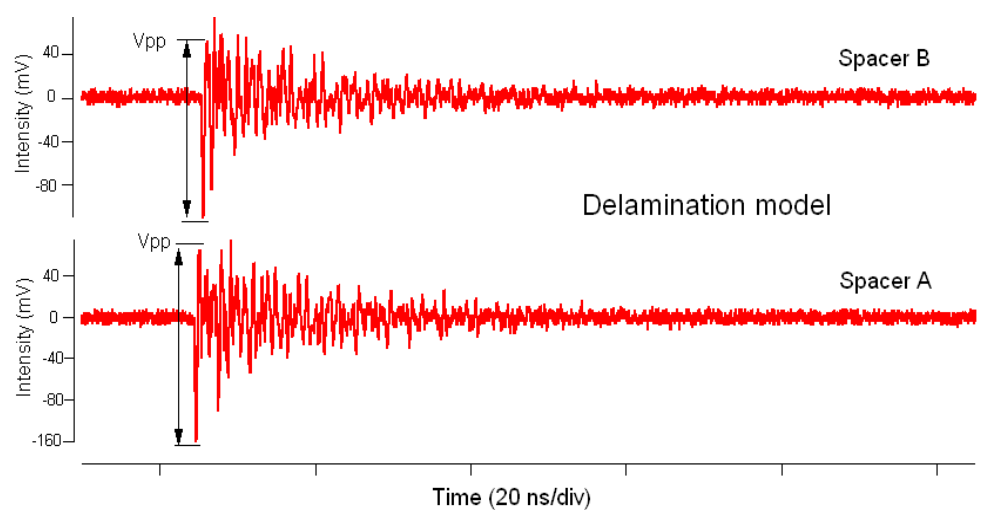

Figure 11 PD induced EM waveform from delamination model measured by external sensors in $66 \mathrm{kV}$ GIS model 
Figures 12-18 show PRPD pattern measured by external spiral type antenna sensor.
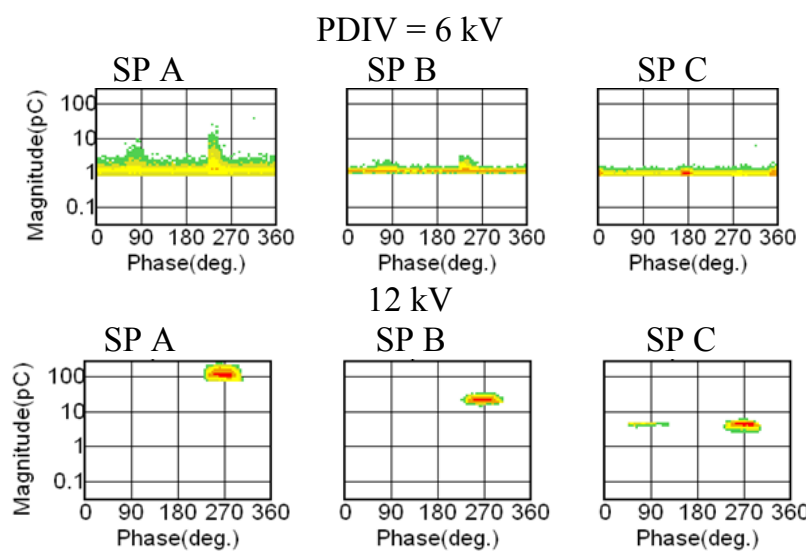

$12 \mathrm{kV}$
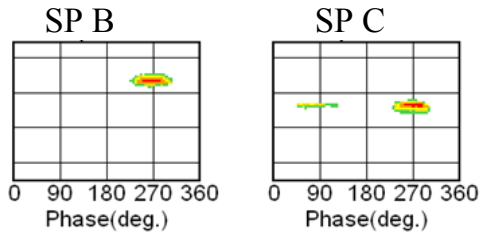

Figure 12. PD Pattern of protrusion on HVC measured by external sensors with spiral antenna in $66 \mathrm{kV}$ GIS

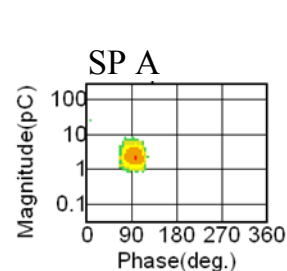

$\mathrm{PDIV}=12.5 \mathrm{kV}$
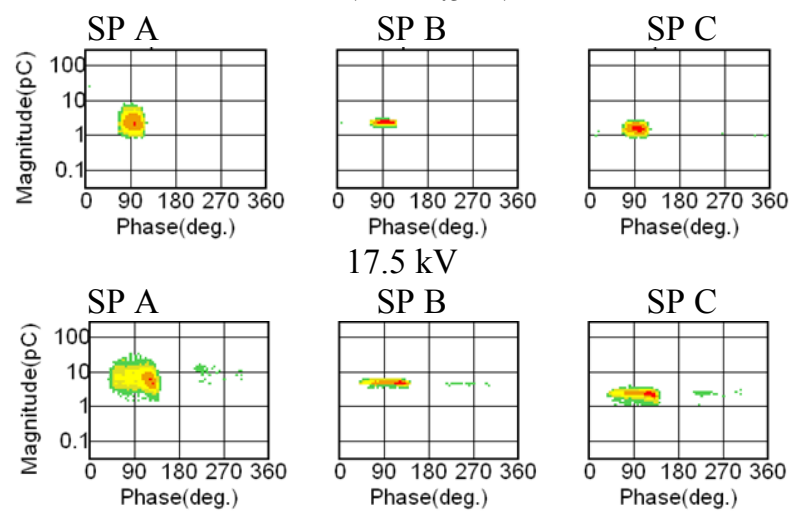

SP B
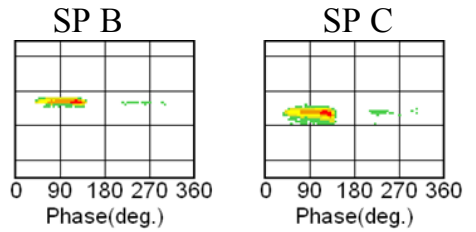

Figure 13. PD Pattern of protrusion on the tank measured by external sensors with spiral antenna in $66 \mathrm{kV}$ GIS

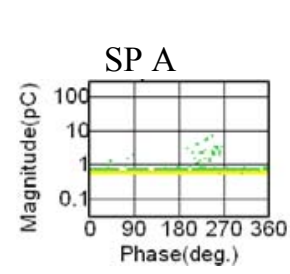

$\mathrm{PDIV}=23 \mathrm{kV}$
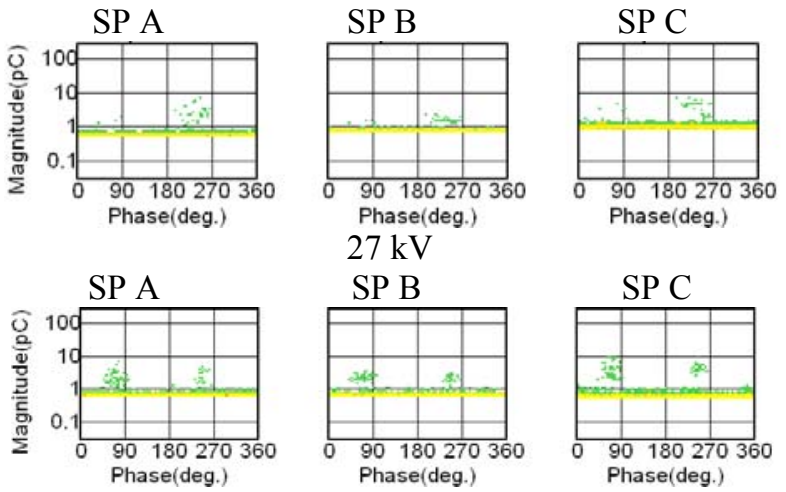

Figure 14. PD Pattern of floating electrode measured by external sensors with spiral antenna in $66 \mathrm{kV}$ GIS 


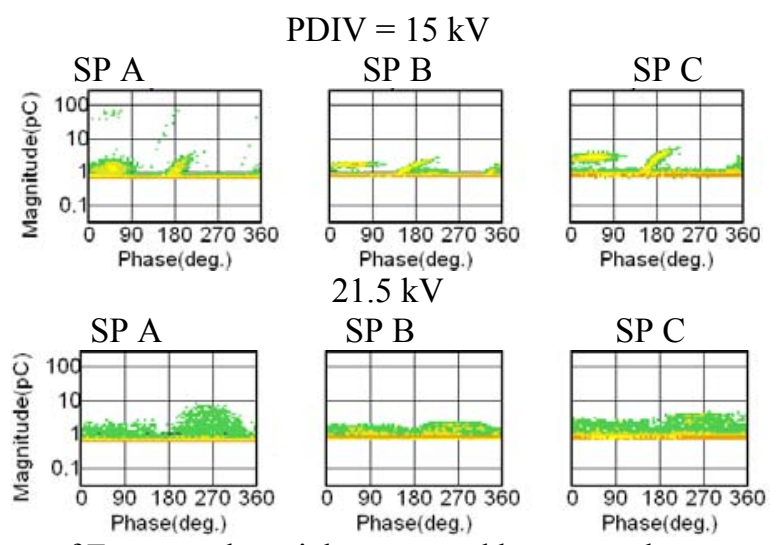

Figure 15. PD Pattern of Free metal particle measured by external sensors with spiral antenna in $66 \mathrm{kV}$ GIS

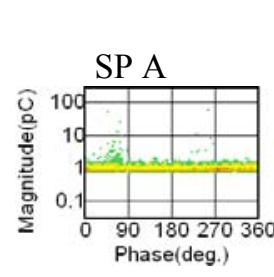

$\mathrm{PDIV}=48 \mathrm{kV}$
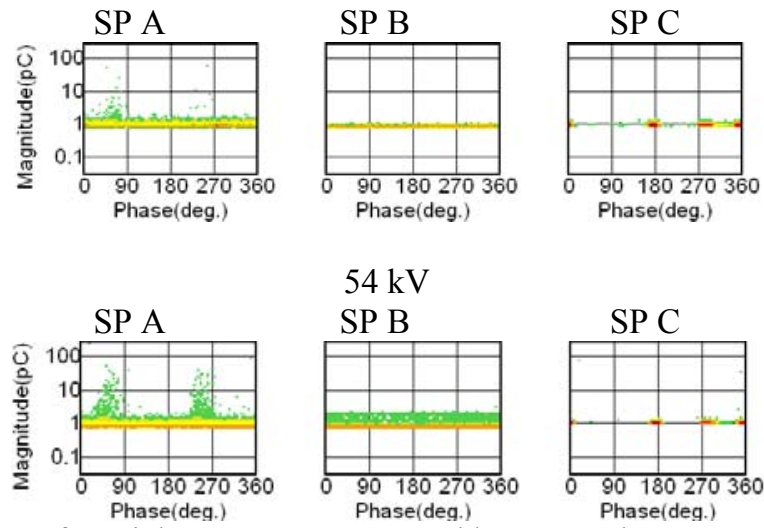

$54 \mathrm{kV}$

SP B
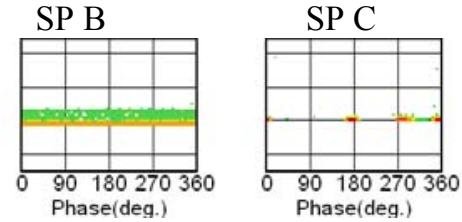

Figure 16. PD Pattern of Particle on spacer measured by external sensors with spiral antenna in $66 \mathrm{kV}$ GIS

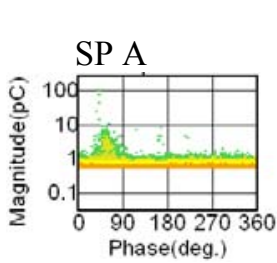

$\mathrm{PDIV}=3 \mathrm{kV}$
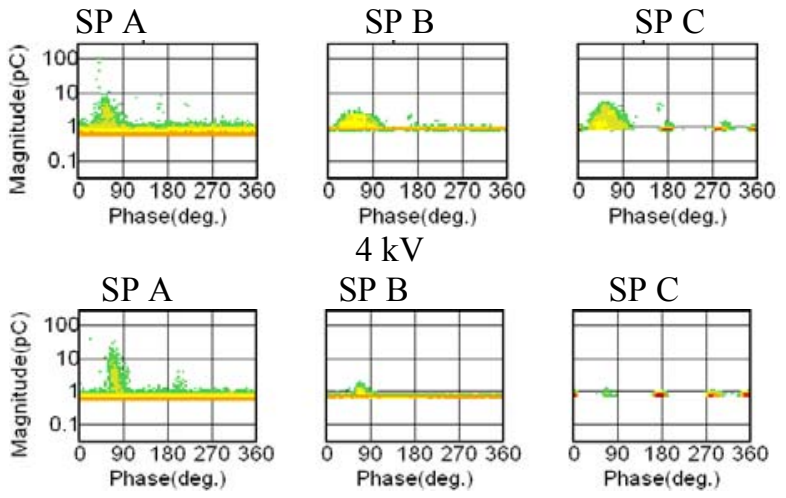

$4 \mathrm{kV}$

SP B
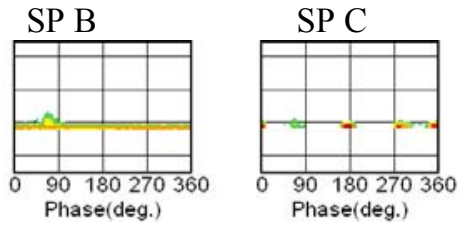

Figure 17. PD Pattern of Aerial Defects measured by external sensors with spiral antenna in 66 kV GIS 

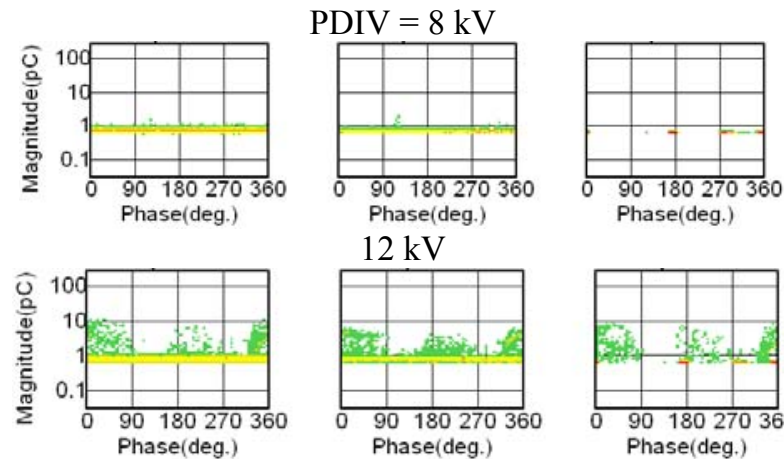

Delamination model

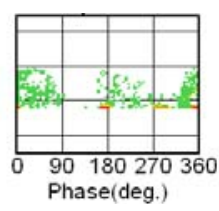

Figure 18. PD Pattern of Delamination model measured by external sensors with spiral antenna in $66 \mathrm{kV}$ GIS

\section{ANALYSIS \& DISCUSSION}

\section{A. Phase Resolved PD Pattern}

The experiment results are analyzed and discussed based on statistical approach, trending, and graph or table. First we examined PRPD pattern data. PRPD patterns presented here were recorded in uni-polar mode with time of acquisition of 120 seconds. Characteristics of PD for pattern recognition and classification are computed from the relation of the voltage phase angle, the discharge magnitude and the repeated existing of PD using statistical analysis.

The PD quantity as function of the phase angle represent the recurrence of PD related to their phase angle [31-33]. The voltage cycle is divided into phase window representing the angle axis $\left(0-360^{\circ}\right)$. The four quantities can be determined in each phase window as follows:

1. The sum of the discharge magnitudes observed in one phase window (discharge amount).

2. The number of discharges observed in one phase window (pulse count).

3. The average value of discharges observed in one phase (mean pulse height).

4. The maximum value of discharge observed in one phase window (maximum pulse height).

Table 1 summarizes the specific PD occurrence phase angle of each artificial defect. Protrusion on high voltage conductor (POC) defect shows that discharges pulses occurred in negative half cycles. The discharges were concentrated around the peak of the negative half cycle of the applied voltage which indicated that the discharges occurrence was mainly influenced by the instantaneous applied voltage. This phenomenon was due to the availability of initial electrons which were easily ejected from needle tip to initiate negative discharges.

Table 1 Specific PD occurrence phase angle of each artificial defect

\begin{tabular}{|c|c|}
\hline Discharges / Defect & Specific Phase \\
\hline Protrusion on HVC (POC) & $270^{\circ}$ \\
\hline Protrusion on Tank (POT) & $90^{\circ}$ \\
\hline Floating electrode (FLOATING) & $225^{\circ} ; 45^{\circ}$ \\
\hline Free metal particle (FMP) & Randomly \\
\hline Particle on spacer (POS) & $45^{\circ} ; 225^{\circ}$ \\
\hline Void / delamination (DEL) & $0^{\circ} ; 180^{\circ}$ \\
\hline- Aerial / GIS outside (OUTSIDE) $^{-----}$ & $67.5^{\circ}$ \\
\hline
\end{tabular}


Protrusion on tank (POT) defect shows that discharges pulses occurred in positive half cycles. It is also influenced by instantaneous applied voltage because positive ions on HV conductor side affect the appearance of negative ion (electron) on the ground side (tank). Then, initial electrons are ejected from needle tip to initiate discharges.

Floating electrode (FLOATING) defect shows that discharges pulses occurred in $225^{\circ}$ and $45^{\circ}$. It indicates that discharges occurred under voltage rise and fall (time derivative of applied voltage $\mathrm{dv} / \mathrm{dt}$ is positive on the left side and negative on the right side). This indicates that discharge occurrence depends on the slope/gradien of the applied voltage.

Free metal particle (FMP) defect shows that discharges pulses occurred as a random in voltage phase. It indicates that the discharges occurrence influenced by the instantaneous applied voltage. As a free particle, they can behave like a protrusion on the conductor/tank or floating metal. Therefore they have combination pattern from protrusion and floating metal.

Particle on spacer (POS) defect shows that discharges pulses occurred in $45^{\circ}$ and $225^{\circ}$. It can be explained that the spacer acts as capacitor in which there are charging and discharging process. Besides that, influence of particle existences give a reason that discharge still depend on instantaneous applied voltage. Therefore they undergo like phase shift because of space charge process and also act as particle.

\section{B. Statistical Characteristic of PD Pattern}

Table 2 summarizes statistical characteristics of PD for various defects. $\mathrm{H} \mathrm{n}(\phi)$ represents the number of the observed discharges in each phase window as a function of the phase angle. Hqn $(\phi)$ is mean pulse height distribution which represents the average amplitude in each phase window as a function of phase angle. Hq $\mathrm{n} \max (\phi)$ represents maximum amplitude in each phase window as a function of phase angle.

Table 2. Statistical Characteristic of PRPD pattern for various defects

\begin{tabular}{|c|c|c|c|c|c|c|}
\hline $\begin{array}{c}\text { Discharges / } \\
\text { Problem }\end{array}$ & $\begin{array}{c}\text { Hq n max } \\
(\phi)+\end{array}$ & $\begin{array}{c}\text { Hq n max } \\
(\phi)-\end{array}$ & Hq n $(\phi)+$ & Hq n $(\phi)-$ & Hn $(\phi)+$ & Hn $(\phi)$ - \\
\hline $\begin{array}{c}\text { Protrusion on HVC } \\
(\text { POC) }\end{array}$ & - & 240.6 & - & 117.5 & - & 185.4 \\
\hline $\begin{array}{c}\text { Protrusion on Tank } \\
(\text { POT) }\end{array}$ & 110 & 22.5 & 21.8 & 1.1 & 154.7 & 4.2 \\
\hline $\begin{array}{c}\text { Floating electrode } \\
\text { (FLOATING) }\end{array}$ & 8.9 & 11.9 & 2.1 & 3.8 & 5.1 & 6.7 \\
\hline $\begin{array}{c}\text { Free metal particle } \\
\text { (FMP) }\end{array}$ & 11.9 & 32.1 & 3.8 & 4.1 & 17.4 & 21.3 \\
\hline $\begin{array}{c}\text { Particle on spacer } \\
\text { (POS) }\end{array}$ & 18.2 & 20.1 & 2.2 & 2.3 & 13.1 & 14.2 \\
\hline $\begin{array}{c}\text { Void / delamination } \\
\text { (DEL) }\end{array}$ & 14.1 & 14.6 & 2.9 & 3.1 & 19.5 & 20.4 \\
\hline $\begin{array}{c}\text { Aerial / GIS outside } \\
(\text { OUTSIDE) }\end{array}$ & 18.6 & 4.8 & 3.5 & 1.8 & 20.5 & 4.7 \\
\hline
\end{tabular}

Table 3 summarizes skewness and kurtosis of PD pattern characteristics for various defects. Skewness is a measure of symmetry, or more precisely, the lack of symmetry. A distribution, or data set, is symmetric if it looks the same to the left and right of the center point. Kurtosis is a measure of whether the data are peaked or flat relative to a normal distribution. That is, data sets with high kurtosis tend to have a distinct peak near the mean, decline rather rapidly, and have heavy tails. Data sets with low kurtosis tend to have a flat top near the mean rather than a sharp peak. 
Table 3. Kurtosis \& Skewness values from various defects

\begin{tabular}{|c|c|c|c|c|c|c|c|}
\hline & $\begin{array}{c}\text { Protrusion on } \\
\text { HVC (POC) }\end{array}$ & $\begin{array}{c}\text { Protrusion on } \\
\text { Tank (POT) }\end{array}$ & $\begin{array}{c}\text { Floating } \\
\text { electrode } \\
\text { (FLOATING) }\end{array}$ & $\begin{array}{c}\text { Free metal } \\
\text { particle (FMP) }\end{array}$ & $\begin{array}{c}\text { Particle on } \\
\text { Spacer (POS) }\end{array}$ & $\begin{array}{c}\text { Void / } \\
\text { delamination } \\
\text { (DEL) }\end{array}$ & $\begin{array}{c}\text { Aerial / GIS } \\
\text { outside } \\
\text { (OUTSIDE) }\end{array}$ \\
\hline ku+ & - & 1.1 & -0.5 & -1.1 & 2 & -1.2 & 1.4 \\
\hline ku- & -1.1 & - & -0.5 & -0.5 & 2 & -1.1 & - \\
\hline sk+ & - & 0.1 & 0 & -0.1 & -0.2 & 0.1 & 0.3 \\
\hline sk- & 0.1 & - & 0 & 0 & 0 & 0.5 & - \\
\hline
\end{tabular}

It can be concluded that there is tendency kurtosis give positive result for protrusion on the tank defect, aerial defect, and particle on the spacer defect and negative result for the rest. On the other side, there is tendency that skewness of all defects almost give symmetric pattern, so skewness value tend to zero value. It can be explained because of the effect of symmetrical role of the electrode system (i.e needle-ground electrode) in producing discharges.

Figure 19 shows apparent charge from different defects measured based on IEC 60270. It was seen that floating electrode (FL) defect gives the largest apparent charge and followed by aerial defects charge. Floating electrode is not connected into conductor or tank (ground), so they will result in big discharge once exceed the threshold. Free metal particle and particle on spacer defects give small apparent charge. Free metal particle (FMP) defect result small apparent charge due to mobile effect, meanwhile particle on spacer (POS) defect result small apparent charge due to combination between spacer existence and small protrusion. From above explanation, the apparent charge results does not seem to be correlated with UHF measurement.

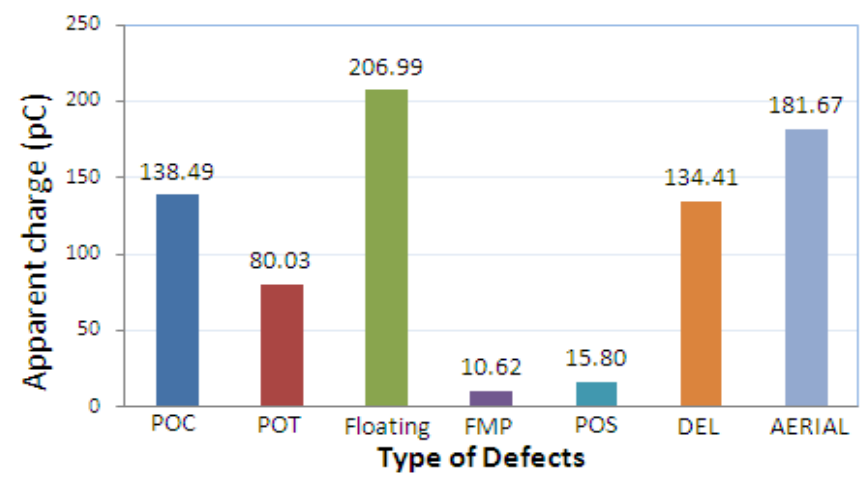

Figure 19. Apparent charge of various defects measured by partial discharge detection in $66 \mathrm{kV}$ GIS

Figure 20 shows Transmission Rate based on Vpp comparison. The transmission rate $\left(\mathrm{T}_{\mathrm{RAB}}\right)$ is defined as a comparison between intensity of $\mathrm{PD}$ induced electromagnetic wave measured by sensor B (length from PD source $=1,5 \mathrm{~m}$ ) compare to one measured by sensor A (length from PD source $=0,5 \mathrm{~m}$ ). The transmission rate $\left(T_{R}\right)$ informs attenuation (damping) characteristics because of the spacer presence and the propagation properties. It was obvious from Figure 20 that the average transmission rate is about $70 \%$ except floating electrode and aerial defect. 


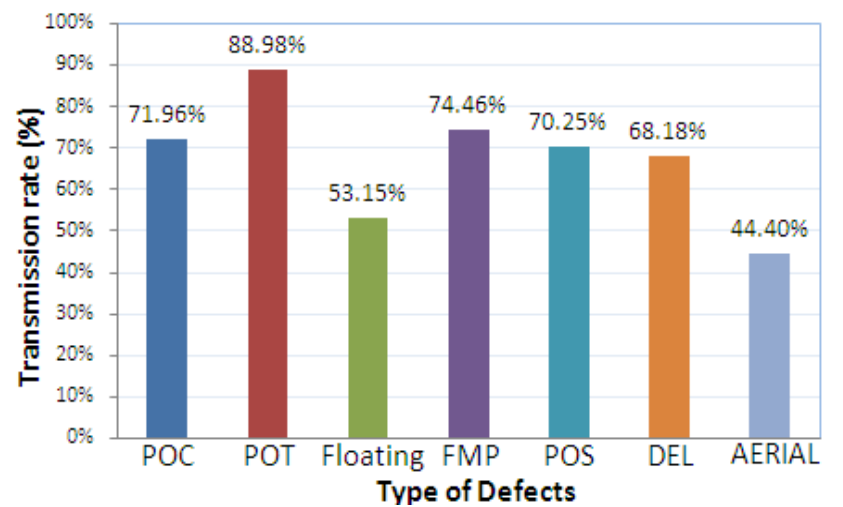

Figure 20. Transmission Rate based on Vpp comparison between 2 sensors on spacer A and spacer B

\section{Conclusion}

We investigated PD pattern from several artificial defects measured with spiral antenna type as the external UHF sensors in $66 \mathrm{kV}$ GIS model. The results showed that PD PRPD Pattern and PD waveform of each defect their own characteristic that differ from each other. Specific PD phase angle and statistical analysis of each artificial defect result various characteristic. Floating electrode defect gives the largest apparent charge the transmission rate of each artificial defect was about $70 \%$. These results are considered to be useful for the enhancement of PD database PD measured by the external sensor.

\section{References}

[1] M. D. Judd, O. Farish, and B.F. Hampton, "The Excitation of UHF Signals by Partial Discharges in GIS”, IEEE Trans. Dielectr. Electr. Insul., Vol. 3, pp.213-228, 1996.

[2] T. Hoshino, H. Koyama, S. Maruyama, and M. Hanai, "Comparison of Sensitivity between UHF Method and IEC 60270 for On-site Calibration in Various GIS," IEEE Trans. Power Delivery, Vol. 21, No. 4, pp. 1948-1953, 2006.

[3] S.M.Hoek, U.Riechert, T.Streh, S.Tenbohlen and K. Feser, "A New Procedure for Partial Discharge Localization in Gas-Insulated Switchgears in Frequency Domain", $14^{\text {th }}$ Int'l. Sympos. High Voltage Eng. (ISH), Paper No.G-05,2005.

[4] S.M. Hoek, M. Koch and M. Heindl,"Propagation Mechanisms of PD Pulses for UHF and Traditional Electrical Measurements", Int'l. Conf. Condition Monitoring and Diagnosis, Paper No. C2-2, 2010.

[5] M. Hanai, F. Endo, S. Okabe, T. Kato, H. Hama, and M. Nagao, "New development for detecting partial discharge using an UHF method and its application to power apparatus in Japan," CIGRE,2006.

[6] S. Okabe, S. Kaneko, M. Yoshimura, H. Muto, C. Nishida and M. Kamei, "Partial Discharge Diagnosis Method Using Electromagnetic Wave Mode Transformation in Gas Insulated Switchgear", IEEE Trans. Dielectr. Electr. Insul., Vol. 14, No. 3, pp. 702-709, 2007.

[7] M. Yoshimura, H. Muto, C. Nishida, M. Kamei, S. Okabe and S. Kaneko, "Propagation Properties of Electromagnetic Wave through T-branch in GIS", IEEE Trans. Dielectr. Electr. Insul., Vol. 14, No. 2, pp.328-333, 2007.

[8] A. J. Reid, and M. D. Judd, "High Bandwidth Measurement of Partial Discharge Pulses in SF6," 14 ${ }^{\text {th }}$ Int'l. Sympos. High Voltage Eng. (ISH), Paper No. G-012, 2005.

[9] M. Hikita, S. Ohtsuka, S. Okabe, J. Wada,T. Hoshino and S. Maruyama. "Influence of Disconnecting Part on Propagation Properties of PD-induced Electromagnetic Wave inModel GIS”, IEEE Trans. Dielectr. Electr. Insul., Vol. 17, No.6, pp.1731-1737, 2010. 
[10] Umar Khayam, Masahiro Kozako, Masayuki Hikita, Tosihiro Hoshino, Shiro Maruyama, Junichi Wada and Shigemitsu Okabe, "Effect of the Presence of Epoxy Spacer on Transmission Rate of Electromagnetic Wave Propagating through T-Branch of $66 \mathrm{kV}$ GIS Model Tank", IEEE Transactions on Dielectric and Electrical Insulation, Volume 20 Issue 6, pp. 2254-2261, December 2013.

[11] M. Hikita, S. Ohtsuka, G. Ueta, S. Okabe,T. Hoshino and S. Maruyama. "Influence of Insulating SpacerType on Propagation Properties of PD-induced Electromagnetic Wave inGIS", IEEE Trans. Dielectr. Electr. Insul., Vol. 17, No.5, pp. 1642-1647,2010.

[12] M. Hikita, S. Otsuka, J. Wada, S. Okabe, T. Hoshino, and S. Maruyama, "Propagation Properties of PD-induced Electromagnetic Wave in $66 \mathrm{kV}$ GIS Model with L Branch Structure", IEEE, Trans. Dielectr. Electr. Insul., Vol.18, No.5, pp.1678-1685, 2011.

[13] M. Hikita, S. Otsuka, S. Okabe, G. Ueta, T. Hoshino, and S. Maruyama, "Propagation Properties of PD-induced Electromagnetic Wave in GIS Model Tank with T Branch Structure", IEEE, Trans. Dielectr. Electr. Insul.,Vol.18, No.1, pp.256-263, 2011.

[14] H. Muto, M. Doi, H. Fujii, M. Kamei,"Resonance characteristics and identification of modes of electromagnetic wave excited by partial discharges in GIS", $11^{\text {th }}$ Int'l. Sympos. High Voltage Eng. (ISH), Vol. 5, pp. 70-73, 1999.

[15] H.Muto, M. Doi, H. Fujii, M. Kamei,"Resonance characteristics and identification of modes of electromagnetic wave excited by partial discharge in GIS", Trans. ElectriEng in Japan, Vol. 131, No.2, pp. 1-11, 2000 (in Japanese).

[16] R. Kurrer, K. Feser,"Attenuation Measurements of Ultra High Frequency Partial Discharge Signals in Gas Insulated Substations", $10^{\text {th }}$ Int'l. Sympos. High Voltage Eng. (ISH), Montreal, Vol. 2, pp. 161-164, 1997.

[17] S. Meijer, Partial Discharge Diagnosis of High Voltage Gas Insulated Systems, Ph.D. Dissertation, TU Delft, 2001.

[18] M.D. Judd, O.Farish and B.F. Hampton, "Modeling Partial Discharge Excitation of UHF Signals in Waveguide Structures using Green's Functions", IEE Proc., Sci., Measurement and Techn., Vol. 143, No. 1, pp.63-70,1996.

[19] M. D. Judd, B.F. Hampton and O Farish,"Partial Discharge Excitation of UHF Modes in a Cylindrical Cavity", $9^{\text {th }}$ Int'l. Sympos. High Voltage Eng. (ISH), Graz, Austria, Vol. 4, pp. 4561-1-4561-4,1995.

[20] S. Kaneko, et al.," Detecting characteristics of various type antennas on partial discharge electromagnetic wave radiating through insulating spacer in Gas Insulated Switchgear", IEEE DEIS Vol. 16, No. 5, pp. 1462-1472, 2009.

[21] Sriyono, Widya Anggoro Putro, Kichi Nishigouchi, Umar Khayam, Suwarno, Masahiro Kozako, Masayuki Hikita, Koji Urano, Chen Min," Sensitivity Verification and Determination of the Best Location of External UHF Sensors for PD Measurement in GIS, IEEE CMD , Bali, Indonesia, 2012.

[22] Sriyono, Yong-Joo Kim, Umar Khayam, Suwarno, Masayuki Hikita,"Characteristics of External Loop Sensor Located near Bushing on Partial Discharge Induced Electromagnetic Wave Measurement", International Journal on Electrical Engineering and Informatics, Volume 5, Number 1, pp. 12-23, March 2013.

[23] Sriyono, Widya Anggoro Putro, Kichi Nishigouchi, Umar Khayam, Suwarno, Masahiro Kozako, Masayuki Hikita, Koji Urano, Chen Min," Sensitivity Verification and Determination of the Best Location of External UHF Sensors for PD Measurement in GIS, IEEE CMD, Bali, Indonesia, 2012.

[24] Widya Anggoro Putro,Sriyono, K. Nishigouchi, Umar Khayam, Suwarno, Masahiro Kozako, Masayuki Hikita, Koji Urano, Chen Min," Influence of Spacer Aperture Size on PD-Induced Electromagnetic Wave Measured with UHF External Sensor in 66 kV GIS Model, IEEE CMD, Bali, Indonesia, 2012.

[25] Widya Anggoro Putro,Sriyono, K. Nishigouci, Umar Khayam, Suwarno, Masahiro Kozako, Masayuki Hikita, Koji Urano, Chen Min," PD Pattern of Various Defects 
Measured by UHF External Sensor on $66 \mathrm{kV}$ GIS Model, IEEE CMD, Bali, Indonesia, 2012.

[26] Joko Muslim, Suwarno, Umar Khayam, Masayuki Hikita," Improvement of Bowtie UHF Antenna Model for Detecting PD in GIS," Procedia Technology, 8C, pp. 217-224. International Conference on Electrical Engineering and Informatics, Malaysia, June 24$25,2013$.

[27] Joko Muslim, Achmad Susilo, Kiichi Nishigouchi, M. Kozako, M. Hikita, Umar Khayam, Suwarno, Enhanced Bowtie UHF Antenna for Detecting Partial Discharge in Gas Insulated Substation, UPEC, Dublin, Ireland, 2013.

[28] Hanalde Andre, Umar Khayam," Design of New Shape Printed Bowtie Antena for Ultra High Frequency Partial Discharge Sensor in Gas-Insulated Substations", International Conference on Information Technology and Electrical Engineering, pp. 365-369, Yogyakarta, Indonesia, October 7-8, 2013.

[29] Inu Suprianto, Umar Khayam, Suwarno, Kiichi Nishigouchi, Masahiro Kozako, Masayuki Hikita,"Design and Implementation of Small Glasses Model as UHF Sensor to Detect Partial Discharge in Gas Insulated Switchgear", International Conference on Sensor, Sensor System, and Actuator, Bandung, Indonesia, May 28, 2014.

[30] Inu Suprianto, Umar Khayam, Suwarno, Kiichi Nishigouchi, Mohamad Kamarol, Masahiro Kozako, Masayuki Hikita, "UHF Sensor Optimization used for Detecting Partial Discharge Emitted Electromagnetic Wave in Gas Insulated Switchgear", International Symposium on Electrical Insulating Material ISEIM, Japan, June, 2014.

[31] J. Jin, J. Jin, C.S. Chang, C. Chang, T. Hoshino, M. Hanai and N. Kobayashi, "Classification of partial discharge events in gas insulated substations using wavelet packet transform and neural network approaches", IEE Proc.-Sci. Meas. Technol., Vol. 153, No. 2, March 2006.

[32] M. D. Judd, B. F. Hampton, W. L. Brown, "UHF Partial Discharge Monitoring for 132 kV GIS", 10th International Symposium on High Voltage Engineering, August 1997.

[33] S. Meijer, E. Gulski and J. J. Smit, "Pattern Analysis of Partial Discharges in SF6 GIS", IEEE Transactions on Dielectrics and Electrical Insulation, Vol. 5 No. 6, December 1998

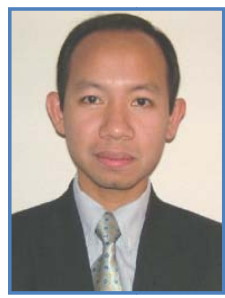

Umar Khayam is an Assistant Professor at School of Electrical Engineering and Informatics, Institut Teknologi Bandung (ITB), Indonesia. He was born in Surakarta, Indonesia in 1975. He received the B.Eng. (cum laude) and M.Eng. degrees in electrical engineering from ITB in 1998 and 2000, respectively. He received the Dr. Engdegree in electrical engineering from Kyushu Institute of Technology (KIT), Japan in 2008. He worked as a Researcher at Hikita Laboratory, KIT during 2008-2009 and 2010-2012. Currently he is the Head of High Voltage and High Current Engineering Laboratory, ITB. Dr. Umar Khayam is the General Secretary of 2012 IEEE International Conference on Condition, Monitoring, and Diagnosis (CMD). He received Best Paper Award in 2005 Korea Japan Symposium on High Voltage Engineering and Electrical Discharge. His research interest is partial discharge measurement and phenomena in electric power apparatus. Dr. Umar Khayam is a member of IEEE.

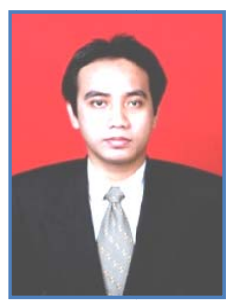

Widya Anggoro Putro is an Engineer in Indonesia Electrical Company. He received the B.Eng. and M.Eng. degrees in electrical engineering from ITB in 2006 and 2012, respectively. He worked as electrical maintenance engineer in Indonesia Electrical Company, PT PLN (Persero) since 20072009. He conducted the research in Kyushu Institute of Technology, Japan during 2011-2012. Since 2012 he has been working in head office of PT PLN. His research interest is partial discharge measurement in gas insulated switchgear. 


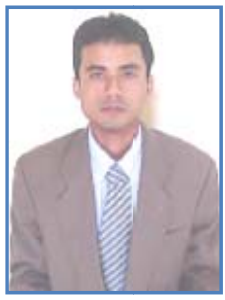

equipment.
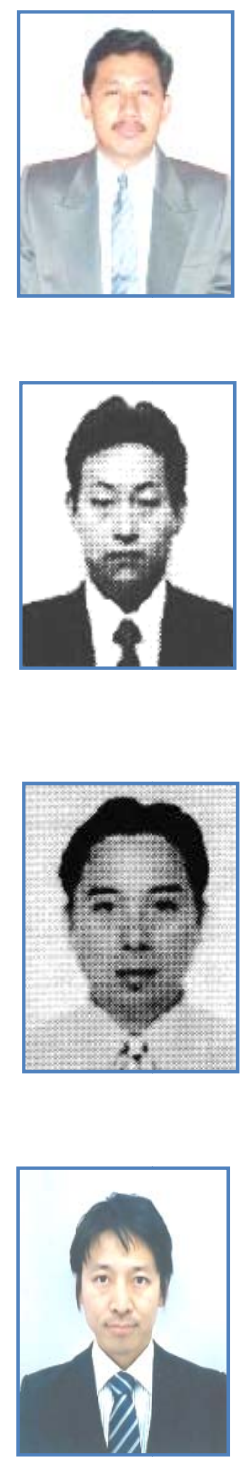

Masahiro Kozako is an Associate Professor at Department of Electrical and Electronic Engineering, Kyusyu Institute of Technology. He was born on 13 August, 1974 in Tokyo. He received the B. Eng., M. Eng., and Dr. Eng. degrees in electrical engineering from Kyushu Institute of Technology in 1997, 1999, and 2002, respectively. He worked at Waseda University for 3 years as an Assistant Professor and a Lecturer, and at Kagoshima National College of Technology for 3 years as an Assistant Professor. He was a Visiting Researcher at the LAPLACE in Université Paul Sabatier, France, from 2011 for a year. His research interests concern the development of new insulating polymer nano-composite materials and the development of diagnostic technique for electric power apparatus. He is a member of the IEEJ and the IEEE. 


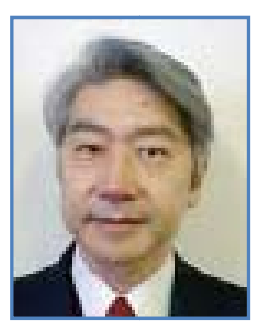

Masayuki Hikita was born in 1953. He received the B.S., M.S. and Dr. degrees in electrical engineering from Nagoya University, Japan, in 1977, 1979, and 1982, respectively. He was Lecture assistant Professor and Associate Professor at Nagoya University in 1982, 1989, and 1992, respectively. Since 1996, he has been a professor of Department of Electrical Engineering, Kyushu Institute of Technology. He was Visiting Scientist at the High Voltage Laboratory in MIT, USA, from 1985 to 1987.

Dr. Hikita has been interested in the development of diagnostic technique of electric power apparatus and insulation system of power electronics device and apparatus. He is a member of the Japan Society of Applied Physics and the IEEJ. 